\title{
Measuring physical activity using accelerometry in 13-15-year-old adolescents: the importance of including non-wear activities
}

\author{
Femke De Meester ${ }^{1, *}$, Ilse De Bourdeaudhuij ${ }^{1}$, Benedicte Deforche ${ }^{1,2}$, \\ Charlene Ottevaere ${ }^{3}$ and Greet Cardon ${ }^{1}$ \\ 'Department of Movement and Sport Sciences, Faculty of Medicine and Health Sciences, Ghent University, \\ Watersportlaan 2, B-9000 Ghent, Belgium: ${ }^{2}$ Department of Human Biometry and Biomechanics, Faculty of \\ Physical Education and Physiotherapy, Vrije Universiteit Brussel, Brussels, Belgium: ${ }^{3}$ Department of Public Health, \\ Faculty of Medicine and Health Sciences, Ghent University, Ghent, Belgium
}

Submitted 2 February 2011: Accepted 16 June 2011: First published online 11 August 2011

\begin{abstract}
Objective: The present study aimed to examine the impact of non-wear activities registered in diaries when using accelerometers to assess physical activity (PA) in young adolescents.

Design: Data arise from a large-scale cross-sectional study on PA. PA was objectively assessed using Actigraph ${ }^{\mathrm{TM}}$ accelerometers (Actigraph MTI, Manufacturing Technology Inc., Pensacola, FL, USA) during seven consecutive days. Non-wear time activity diaries were provided to register the activities for which the accelerometer was removed. After correction to deal with over-reporting, the registered minutes of PA were used to replace periods of non-wear time measured by the accelerometer. Setting: Between October 2008 and May 2009 adolescents were recruited by home visits in Ghent (Belgium).

Subjects: Young adolescents ( $n$ 513; 48.6\% boys) aged 13 to 15 years.

Results: Of the total sample, $49.9 \%$ registered at least one activity of moderate to vigorous intensity in the non-wear time activity diary. More adolescents registered an activity performed on a weekday than on a weekend day and the registered mean number of minutes of moderate to vigorous PA were higher on weekend days. Repeated-measures (M)ANOVA tests revealed a significant difference between the mean minutes with and without non-wear activities for all PA intensities, regardless of adolescents' socio-economic status or gender. More adolescents achieved the PA recommendations after inclusion of the non-wear activities irrespective of accelerometer thresholds used.

Conclusions: The collection of information regarding non-wear time by non-wear time activity diaries when using accelerometers in 13-15-year-old adolescents can lead to different PA outcomes at the individual level and therefore can improve the ability to accurately measure PA.
\end{abstract}

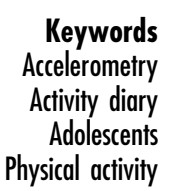

Regular physical activity (PA) is a key protective factor for health. Among youngsters, a physically active lifestyle can contribute to concurrent ${ }^{(1-4)}$ and future health benefits ${ }^{(4,5)}$. Based on these findings, PA recommendations for school-aged adolescents subscribe participation in PA of at least moderate to vigorous intensity (MVPA) for $60 \mathrm{~min} / \mathrm{d}^{(3,6)}$. Consequently, accurate assessment methods for the amount and intensity of PA are necessary to examine the relationship between PA and specific health outcomes and to evaluate the effectiveness of PA interventions ${ }^{(7)}$.

During the last decade, accelerometers have emerged as one of the most commonly used tools to objectively assess the frequency, duration and intensity of free-living PA. Recent reviews have designated accelerometry as valid and reliable for quantifying PA levels in adolescents ${ }^{(8-10)}$.
Furthermore, accelerometers are small, lightweight and thus unobtrusive. Following the advantages of the device, several large-scale observational and intervention studies used accelerometers in children and adolescents ${ }^{(11-15)}$. Nevertheless, different challenges are related to accelerometry, of which several are inherent to methodological considerations concerning the data-reduction analysis process ${ }^{(16)}$.

When reducing and cleaning accelerometer data, investigators are often confronted with missing data arising from accelerometers that are not worn consistently during the entire measurement period ${ }^{(9,17,18)}$. Non-wear time can be due to participants' non-compliance to the study protocol or to legitimate reasons for removing the accelerometer, such as aquatic activities (e.g. swimming, bathing) and activities where safety regulations prohibit 
activity monitors, such as some school or organized sport activities. Consequently, some physical activities are not recorded, which may lead to an underestimation of accelerometer-determined PA.

The results of previous studies demonstrate that the proportion of missing data due to non-wear of an activity monitor is highest in adolescence ${ }^{(19)}$. Currently, no standards exist concerning the optimal approach to deal with non-wear time. A common approach is deleting consecutive minutes of zero output. Although different studies have applied this method ${ }^{(9,20-22)}$, removal of zero output can result in days for which the minimum number of minutes to obtain a valid day cannot be reached. Exclusion of those invalid days can result in individuals failing to reach the postulated number of valid days for inclusion in the study. As a consequence, the exclusion of invalid days and individuals failing to reach the required number of valid days can lead to selection bias ${ }^{(23)}$. Such bias may have severe implications for estimation of individual PA and may lead to a considerable misclassification of individuals or groups.

Some researchers have attempted to obtain more unbiased estimates of accelerometer-determined PA levels by imputation techniques. The idea of imputation is to use observed accelerometer data to assist in predicting missing values of non-wear time ${ }^{(23)}$. These techniques are affected by the proportion of missing data and the correlation of activity across days of the week ${ }^{(23)}$. The lower percentage of missing data on weekdays and the higher correlation between weekday activity levels imply that when using imputation, weekday activity levels will be more accurate than weekend day activity levels ${ }^{(23)}$.

Another method to reduce the impact of non-wear time is the use of non-wear time activity diaries which can be applied to register activities performed during non-wear time. The information registered in such diaries can complete the accelerometer data. To our knowledge, non-wear time activity diaries were distributed in different studies. However, none of these studies has described if, and how, the information obtained from diaries was handled ${ }^{(24-26)}$. Recently, a study by Ottevaere et al. ${ }^{(27)}$ investigated the additional value of non-wear time activity diaries when using accelerometers among 213 Belgian adolescents aged 12-18 years. The results revealed that including information obtained from non-wear time activity diaries can lead to significantly different outcomes at the individual level.

Thus, collection of information regarding activities performed during non-wear time could be promising in mining methodological issues inherent to the datareduction process. This method could reduce the known source of bias inherent to missing data of non-wear time and considerably improve the ability to accurately measure PA in adolescents. However, the area concerning inclusion of non-wear activities when using accelerometers is largely unexplored. Particularly in young adolescence ( $\leq 15$ years) this area needs more attention. After all, the participation in formal and informal sports activities peaks in young adolescence from age 12 to 14 years ${ }^{(28)}$ but is characterized by a particularly steep decline from age 15 years onwards ${ }^{(29)}$. Furthermore, more adolescent boys and adolescents of high and medium socio-economic status (SES) participate in organized sports activities than adolescent girls and adolescents of low SES ${ }^{(30,31)}$. The age, gender and SES differences in sports participation and differences in missing data between weekend days and weekdays ${ }^{(23)}$ can be reflected in the registration of activities in the nonwear time activity diary and in the impact of including non-wear activities.

The present study aimed to examine: (i) the registration of non-wear activities in non-wear time activity diaries; (ii) the type of non-wear activities registered in non-wear time activity diaries; (iii) the impact of including non-wear activities on PA summary variables and on the classification according to current PA recommendations; and (iv) differences in impact of including non-wear activities according to gender, SES, PA levels and days of the week (week; weekend), when using accelerometers to assess PA in young adolescents.

\section{Methods}

\section{Participants and study design}

Data for the present study arise from a large-scale Belgian cross-sectional study on PA in adolescents. Recruitment took place in Ghent between October 2008 and May 2009. Participants were recruited by home visits in a random sample of 1399 adolescents, aged 13-15 years. Of the invited adolescents, 59.1\% ( $n$ 637; 49.4\% boys) consented to participate. Written consent was obtained from all participants and the adolescents' parent or legal guardian. The study received approval from the Ethics Committee of Ghent University Hospital.

\section{Measures}

\section{Physical activity}

PA was objectively assessed using Actigraph ${ }^{\text {TM }}$ accelerometers model GT1M (Actigraph MTI, Manufacturing Technology Inc., Pensacola, FL, USA). The Actigraph accelerometer is one of the most commonly used motion sensors in PA research ${ }^{(32)}$. The GT1M model uses a unidirectional accelerometer sensitive to accelerations ranging from $0.05 \mathrm{~g}$ to $2 \cdot 00 \mathrm{~g}$ in the vertical plane, with a frequency response of $0 \cdot 25$ to $2 \cdot 50 \mathrm{~Hz}^{(33)}$. In the present study, $60 \mathrm{~s}$ epochs were used to collect data ${ }^{(25,34-36)}$.

The adolescents were asked to wear an accelerometer for seven consecutive days, including two weekend days. Secured by an elastic belt, the accelerometers were worn on the right hip, above the iliac crest. At the end of the measurement period, the accelerometers were collected and the stored data were downloaded to a computer (Actilife software version $4 \cdot 1 \cdot 0$ ). 


\begin{tabular}{|cccl|}
\hline Date & $\begin{array}{c}\text { Point in time the } \\
\text { accelerometer was removed } \\
\text { point in time you put the } \\
\text { accelerometer back on }\end{array}$ & $\begin{array}{c}\text { Reason for removing } \\
\text { the accelerometer }\end{array}$ & $\begin{array}{c}\text { Description of the } \\
\text { activity }\end{array}$ \\
\hline $17 / 02 / 09$ & $7 \cdot 25-7 \cdot 55$ & Shower & \\
$17 / 02 / 09$ & $13 \cdot 10-14 \cdot 50$ & Physical education & $\begin{array}{l}50 \text { min. baseball } \\
\text { (trampoline) }\end{array}$ \\
$18 / 02 / 09$ & $7 \cdot 20-7 \cdot 40$ & Shower & \\
$18 / 02 / 09$ & $9 \cdot 20-11 \cdot 00$ & Swimming & Swimming laps \\
$19 / 02 / 09$ & $7 \cdot 24-7 \cdot 43$ & Shower & \\
$19 / 02 / 09$ & $18 \cdot 00-19 \cdot 30$ & Basketball & Training + shower \\
\hline
\end{tabular}

Fig. 1 Example of a completed non-wear time activity diary

\section{Non-wear activities}

In addition to accelerometer-determined activity assessment, non-wear time activity diaries were provided to register all activities for which the accelerometer was removed (except for sleeping). The adolescents were asked to wear the accelerometer during waking hours but to remove the accelerometer for aquatic activities and for activities that prohibit activity monitors. A non-wear time activity diary is a pre-printed registration form to write down when the accelerometer is removed and when it is put back on, the kind of activities the adolescent is involved in when the accelerometer is not worn, as well as a description of those activities. At the end of the measurement period, the diaries were collected and the investigator went through the registered activities together with the adolescent, to verify the completeness. Fig. 1 provides an example of a completed diary.

The non-wear activities were classified as sedentary behavior (SED), light PA (LPA), moderate PA (MPA) or vigorous PA (VPA), according to their MET (metabolic equivalent task) values estimated from the Compendium of Energy Expenditure for Youth ${ }^{(37)}$ (SED, <1.5 MET; LPA, <3 MET; MPA, 3-6 MET; VPA, $\geq 6$ MET). As stated by Harrell et $a l^{(38)}$, the adult compendium ${ }^{(39)}$ is unsuitable for energy estimation in children before the age of 15 years given the difference in RMR and energy costs of everyday activities between children and adults.

The registered number of minutes MPA and VPA were multiplied by a correction factor, assuming that during a given time period not all PA can be performed at the same intensity. For example, research by Fairclough and Stratton demonstrated that during regular physical education classes, the actual percentage of time spent in MVPA was approximately $37 \%{ }^{(40)}$. Furthermore, different studies have stated that self-reported PA is an overestimation of the actual time spent in PA. By using a correction factor $(\mathrm{CF})^{(12,27)}$ according to type of activity (organized, $\mathrm{CF}=0 \cdot 8$; competition, $\mathrm{CF}=0.95$; curricular or leisure time, $\mathrm{CF}=0.5$ ), the actual time spent in MPA and VPA could be approached and the issue of over-reporting was dealt with.

\section{Data reduction}

The data-reduction software MeterPlus version $4 \cdot 0$ (Santech Inc., La Jolla, CA, USA) was used to screen, clean and score the accelerometer data. In the accelerometer data-reduction process, time periods of at least $1 \mathrm{~h}$ of consecutive zeros were removed assuming the accelerometer was unworn $^{(40,41)}$. Whenever applicable, these consecutive zeros were, after the accelerometer data-scoring process, replaced by the corrected number of minutes MPA and VPA registered in the diaries.

To score the accelerometer data, threshold ranges were set to distinguish time spent in MPA and VPA. Different thresholds have been published ${ }^{(43-45)}$ and a lack of consensus on the most suitable thresholds for analysing accelerometer data in adolescents exists ${ }^{(46)}$. Based on the conclusions made in the recent review of Trost et al. ${ }^{(47)}$ and the review of Reilly et $a l^{(8)}$, the thresholds of Puyau et al. ${ }^{(45)}$ (MPA, 3200-8199 counts/min; VPA, $\geq 8200$ counts/ min) were used for the main objectives of the present study. Additionally, the Freedson age-specific equation ${ }^{(48)}$ was used along with the thresholds of Puyau et al. ${ }^{(45)}$ to illustrate the impact of including non-wear activities on the classification of adolescents according to current PA recommendations. This was done to elucidate if including non-wear activities registered in diaries can lead to different PA outcomes and can improve the ability to accurately measure PA irrespective of the cut-off points used.

For inclusion in data analysis, the required total accumulated minutes registered by the accelerometer and diary were $600 \mathrm{~min}$ for weekdays and $480 \mathrm{~min}$ for weekend days considering the differences in sleeping patterns for weekdays and weekend days in adolescents ${ }^{(49)}$. Furthermore, three valid weekdays and one valid weekend day of monitoring were needed to obtain reliable estimates ${ }^{(18,50,51)}$.

\section{Data analyses}

Statistical analyses were conducted using the SPSS statistical software package version $17 \cdot 0$ (SPSS Inc., Chicago, IL, USA). $P$ values $<0 \cdot 05$ were considered significant. Tests for normal distribution revealed skewed PA variables. 
To obtain distributions that more closely approximated symmetry, logarithmic transformations were conducted and the logarithmic-transformed variables were used in the analyses. For ease of interpretation, summary data of untransformed PA variables are reported in $\mathrm{min} / \mathrm{d}$.

Descriptive statistics were used to provide information about different aspects: sample characteristics and registration, reported duration and type of non-wear activities in the diaries. To check if registering at least one activity of moderate or vigorous intensity in the diary was associated with adolescents' gender, SES and day of the week, Pearson's $\chi^{2}$ was calculated. The educational level of the adolescent's parents was used as a proxy measure of SES ${ }^{(52)}$. Adolescents were classified as high SES if one of the parents attained college or university education level. Paired-samples $t$ tests were used to compare the mean minutes of MVPA registered in the diary between weekdays and weekend days.

The percentage of non-wear time visible in the accelerometer data that was reported in the diaries and the agreement between the reported duration of non-wear activities and the duration of zero counts in the accelerometer data were investigated in a subsample ( $n$ 50, mean age $14 \cdot 1$ (SD $0 \cdot 9$ ) years, $52 \cdot 0 \%$ male, $27 \cdot 7 \%$ of low SES). Independent-samples $t$ tests were used to compare whether the level of agreement between reported duration of non-wear activities and duration of zero counts differed according to adolescents' SES and gender.

Furthermore, in the same subsample, Pearson's $\chi^{2}$ test was conducted to investigate if registering at least one activity of moderate or vigorous intensity in the diary was associated with the day of monitoring (first or second) and paired-samples $t$ tests were conducted to compare the mean registered minutes of MVPA between the first and second day of monitoring.

In the total data set, differences in mean minutes of MPA, VPA and MVPA with and without inclusion of non-wear activities for weekdays, weekend days and total week were examined using repeated-measures (M)ANOVA tests, with gender (boys, girls) and SES (low, high) as between-subject factors and non-wear activities (with, without) as within-subject factor.

MedCalc $11 \cdot 4 \cdot 2 \cdot 0$ (Medcalc Software, Mariakerke, Belgium) was used to calculate bias of error and limits of agreement at the individual level by Bland-Altman analysis $^{(53)}$, plotting the difference between PA data with and without inclusion of the non-wear activities against the average of both methods. Limits of agreement were defined as mean bias $\pm 1.96 \mathrm{SD}$. Pearson's correlation analyses were conducted to determine the relationship between the differences in PA data with and without inclusion of the non-wear activities and the average of both methods.

Percentages of adolescents achieving the recommendation ( $\geq 60 \mathrm{~min} \mathrm{MVPA} / \mathrm{d}$ ), with and without inclusion of the non-wear activities, ware calculated using the thresholds of Puyau et al. ${ }^{(45)}$ and the age-specific equation of Freedson ${ }^{(48)}$. Furthermore, the proportion of agreement between the classification of adolescents according to the PA recommendations with and without inclusion of the non-wear activities was calculated using kappa statistics.

\section{Results}

\section{Description of the sample}

Descriptive statistics are reported in Table 1 . Complete data ( $\geq 600 \mathrm{~min} /$ weekday for a minimum of three weekdays and $\geq 480 \mathrm{~min} /$ weekend day for a minimum of one weekend day) were collected from 513 adolescents (80.5\%; $48.7 \%$ boys, $28.2 \%$ low SES, mean age 14.6 (SD $0 \cdot 9$ ) years). For six adolescents the inclusion of nonwear activities was a prerequisite to achieve the required total accumulated minutes registered time for the postulated number of valid days. Adolescents with complete data accumulated significantly more $(t=-22 \cdot 71, \quad P \leq 0 \cdot 001)$ registered time than excluded adolescents.

Table 1 Descriptive data for the study population: young adolescents aged 13-15 years, Ghent, Belgium, October 2008-May 2009

\begin{tabular}{|c|c|c|c|c|c|c|}
\hline \multirow{2}{*}{ Gender } & \multicolumn{2}{|c|}{$\begin{array}{l}\text { Adolescents included } \\
(n 513) \%\end{array}$} & \multicolumn{2}{|c|}{$\begin{array}{l}\text { Adolescents excluded } \\
(n 124) \%\end{array}$} & \multirow{2}{*}{$\frac{x^{2}}{0.81}$} & \multirow{2}{*}{$\frac{P}{0.43}$} \\
\hline & \multirow{2}{*}{\multicolumn{2}{|c|}{$48 \cdot 7$}} & \multirow{2}{*}{\multicolumn{2}{|c|}{$53 \cdot 2$}} & & \\
\hline Males & & & & & & \\
\hline Females & \multicolumn{2}{|c|}{$51 \cdot 3$} & \multicolumn{2}{|c|}{$46 \cdot 8$} & & \\
\hline SES & & & & & $1 \cdot 69$ & $0 \cdot 19$ \\
\hline Low SES & \multicolumn{2}{|c|}{$28 \cdot 2$} & \multicolumn{2}{|c|}{$35 \cdot 6$} & & \\
\hline High SES & \multicolumn{2}{|c|}{$71 \cdot 8$} & \multicolumn{2}{|c|}{$65 \cdot 4$} & & \\
\hline \multirow{4}{*}{$\begin{array}{l}\text { BMI } \\
\text { Normal or underweight } \\
\text { Overweight or obese }\end{array}$} & \multirow{3}{*}{\multicolumn{2}{|c|}{$\begin{array}{l}84 \cdot 1 \\
15 \cdot 9\end{array}$}} & & & 0.02 & 0.90 \\
\hline & & & \multirow{2}{*}{\multicolumn{2}{|c|}{$\begin{array}{l}84 \cdot 6 \\
15 \cdot 4\end{array}$}} & & \\
\hline & & & & & & \\
\hline & Mean & SD & Mean & SD & $t$ & $P$ \\
\hline Age (years) & $14 \cdot 56$ & 0.89 & $14 \cdot 49$ & 0.87 & -0.778 & 0.44 \\
\hline Total number of minutes registered time (min) & $5969 \cdot 26$ & $1650 \cdot 69$ & $2467 \cdot 03$ & $960 \cdot 85$ & $-22 \cdot 71$ & $\leq 0.001$ \\
\hline
\end{tabular}

SES, socio-economic status.

${ }^{*}$ Difference is significant at $P \leq 0.05$. 
Table 2 Descriptive data concerning the registration of non-wear activities in the non-wear time activity diaries

\begin{tabular}{|c|c|c|}
\hline & $n$ & $\%$ \\
\hline Adolescents with non-wear activities registered in their diary (included in present study) & 433 & $84 \cdot 4$ \\
\hline Adolescents without non-wear activities registered in their diary (included in present study) & 48 & $9 \cdot 4$ \\
\hline Adolescents who did not return their diary (included in present study) & 32 & $6 \cdot 2$ \\
\hline Adolescents with an activity of moderate or vigorous intensity registered in their diary & 255 & $49 \cdot 7$ \\
\hline$\ldots$ on $1 \mathrm{~d}$ & 113 & $22 \cdot 0$ \\
\hline$\ldots$ on $2 \mathrm{~d}$ & 82 & $16 \cdot 0$ \\
\hline$\ldots$ on $3 \mathrm{~d}$ & 27 & $5 \cdot 3$ \\
\hline$\ldots$ on $4 \mathrm{~d}$ & 16 & $3 \cdot 1$ \\
\hline$\ldots$ on $5 \mathrm{~d}$ & 10 & $1 \cdot 9$ \\
\hline ... on $6 \mathrm{~d}$ & 6 & $1 \cdot 2$ \\
\hline$\ldots$ on $7 \mathrm{~d}$ & 1 & 0.2 \\
\hline ... on a weekday & 209 & $40 \cdot \overline{7}$ \\
\hline$\ldots$ on a weekend day & 123 & $24 \cdot 0$ \\
\hline Activities of moderate or vigorous intensity registered in the diaries & 515 & $100 \cdot 0$ \\
\hline Swimming: swimming laps, playing in the pool & 133 & $25 \cdot 8$ \\
\hline Ball games: baseball, basketball, European handball, hockey, soccer, volleyball, rugby & 110 & $21 \cdot 4$ \\
\hline Structured physical activities: physical education, play and sport & 81 & $15 \cdot 7$ \\
\hline Gymnastics: gymnastics, trampoline & 50 & $9 \cdot 7$ \\
\hline Martial arts: karate, judo, kick boxing, martial arts & 32 & $6 \cdot 2$ \\
\hline Dancing: dancing, ballet, partying (mostly dancing) & 31 & $6 \cdot 0$ \\
\hline Water activities: sailing, rowing, surfing (body or board), kayaking, skindiving & 14 & $2 \cdot 7$ \\
\hline Athletics: athletics (track and field) - jumping, running/jogging & 13 & $2 \cdot 5$ \\
\hline Racquet sports: badminton, table tennis, tennis, squash & 13 & $2 \cdot 5$ \\
\hline Unstructured outdoor play/playing with young children & 13 & 2.5 \\
\hline Walking & 8 & $1 \cdot 6$ \\
\hline Fitness training: calisthenics, aerobics/health hustle, skipping/jump rope & 7 & 1.4 \\
\hline Riding a bike & 4 & $0 \cdot 8$ \\
\hline Other activities: performing on stage & 3 & 0.6 \\
\hline Climbing: rockclimbing & 2 & 0.4 \\
\hline Motor-cross & 1 & $0 \cdot 2$ \\
\hline
\end{tabular}

There were no significant differences between included and excluded participants in age, BMI, SES and gender distribution.

\section{Activities registered in non-wear time activity diary}

Descriptive data concerning the registration of non-wear activities are given in Table 2 .

No difference was found between the first and second monitoring day in the percentage of adolescents registering at least one activity of moderate or vigorous intensity in the diary $(12.5 \%$ and $12.0 \%$, respectively) and in the mean reported duration of non-wear activities $(8 \cdot 7$ (sD 24.6) $\mathrm{min} / \mathrm{d}$ and $10 \cdot 3(\mathrm{sD} \mathrm{30} \cdot 6) \mathrm{min} / \mathrm{d}$ respectively; $t=-0 \cdot 08, P=\mathrm{NS})$.

Adolescents' gender and SES were not significantly associated with registering at least one activity of moderate or vigorous intensity in the diary. In total, 515 activities were registered and included in the PA data. Swimming and ball games counted together for almost half of the activities ( $25 \cdot 8 \%$ and $21 \cdot 4 \%$, respectively). The registered activities counted for $10 \cdot 2$ (SD 18.5) min MVPA/d. The mean registered minutes of MVPA was significantly lower for weekdays $(8.4(\mathrm{SD} 16 \cdot 5) \mathrm{min} /$ weekday) than for weekend days $(14 \cdot 8(\mathrm{sD} 36 \cdot 2) \mathrm{min} /$ weekend day; $t=2 \cdot 0, P=0 \cdot 05)$.

Overall, $60 \cdot 0 \%$ of the periods of non-wear time visible in the accelerometer data was described in the diaries. The reported duration of the non-wear activities was an overestimation $(117 \cdot 4 \%)$ of the non-wear time identified by accelerometer software. The percentage of overestimation did not depend on adolescents' SES $(t=-0 \cdot 778$, $P=\mathrm{NS})$ and gender $(t=-1 \cdot 796, P=\mathrm{NS})$.

\section{Moderate, vigorous and moderate-to-vigorous physical activity with and witbout inclusion of non-wear activities}

Table 3 shows the mean minutes of MPA, VPA and MVPA with and without inclusion of the non-wear activities for the total sample and separately for boys, girls, low- and highSES adolescents. A distinction was made between mean minutes for weekdays, weekend days and total week.

Repeated-measures (M)ANOVA tests revealed a significant main effect of non-wear activities (NWA). For all intensities (MPA, VPA and MVPA), the mean number of minutes was significantly higher after including the non-wear activities (Table 3). The increase in MPA, VPA and MVPA was significant for weekdays (MPA: $F_{\mathrm{NWA}}=58 \cdot 7, P \leq 0 \cdot 001$; VPA: $F_{\mathrm{NWA}}=96 \cdot 6, \quad P \leq 0 \cdot 001 ;$ MVPA: $\left.F_{\mathrm{NWA}}=129 \cdot 8, \quad P \leq 0 \cdot 001\right)$, weekend days (MPA: $F_{\mathrm{NWA}}=26 \cdot 6, P \leq 0 \cdot 001$; VPA: $F_{\mathrm{NWA}}=$ 58.7, $P \leq 0 \cdot 001$; MVPA: $\left.F_{\mathrm{NWA}}=64 \cdot 8, P \leq 0 \cdot 001\right)$ and total week (MPA: $F_{\mathrm{NWA}}=64 \cdot 0, P \leq 0 \cdot 001 ; \mathrm{VPA}: F_{\mathrm{NWA}}=121 \cdot 4$, $P \leq 0 \cdot 001$; MVPA: $\left.F_{\mathrm{NWA}}=146 \cdot 3, P \leq 0 \cdot 001\right)$.

A significant NWA-by-gender $(G)$ interaction was found for total week MPA $\left(F_{\mathrm{NWA}} \times \mathrm{G}=5 \cdot 3, P \leq 0 \cdot 05\right)$ and VPA $\left(F_{\mathrm{NWA} \times \mathrm{G}}=10 \cdot 9, \quad P=0 \cdot 001\right)$. A similar NWA-by-gender interaction effect was found for weekday MPA $\left(F_{\mathrm{NWA} \times \mathrm{G}}=\right.$ $6 \cdot 1, P \leq 0 \cdot 05)$ and VPA $\left(F_{\mathrm{NWA} \times \mathrm{G}}=8 \cdot 4, P \leq 0 \cdot 01\right)$. For both 
Table 3 Time spent $(\mathrm{min} / \mathrm{d})$ in moderate physical activity (MPA), vigorous physical activity (VPA) and moderate-to-vigorous physical activity (MVPA) registered with accelerometers with (CSA+NWA) and without (CSA) inclusion of the non-wear activities, for the total sample and stratified by gender and socio-economic status (SES), among young adolescents ( $n 513 ; 48.6 \%$ boys) aged $13-15$ years, Ghent, Belgium, October 2008-May 2009

\begin{tabular}{|c|c|c|c|c|c|c|c|c|c|c|c|c|}
\hline \multirow[b]{3}{*}{ Total week } & \multicolumn{4}{|c|}{ MPA $(\min / d)$} & \multicolumn{4}{|c|}{$\operatorname{VPA}(\min / \mathrm{d})$} & \multicolumn{4}{|c|}{ MVPA $(\mathrm{min} / \mathrm{d})$} \\
\hline & \multicolumn{2}{|c|}{ CSA } & \multicolumn{2}{|c|}{$\mathrm{CSA}+\mathrm{NWA}$} & \multicolumn{2}{|c|}{ CSA } & \multicolumn{2}{|c|}{$\mathrm{CSA}+\mathrm{NWA}$} & \multicolumn{2}{|c|}{ CSA } & \multicolumn{2}{|c|}{$\mathrm{CSA}+\mathrm{NWA}$} \\
\hline & Mean & SD & Mean & SD & Mean & SD & Mean & SD & Mean & SD & Mean & SD \\
\hline Total sample (100\%) & $21 \cdot 39$ & $14 \cdot 94$ & $26 \cdot 79$ & $19 \cdot 48$ & $1 \cdot 30$ & $2 \cdot 42$ & $6 \cdot 19$ & $12 \cdot 36$ & $22 \cdot 69$ & $15 \cdot 89$ & $32 \cdot 96$ & $23 \cdot 65$ \\
\hline Boys (48.7\%) & $27 \cdot 14$ & $17 \cdot 41$ & $31 \cdot 31$ & $20 \cdot 11$ & 1.69 & $2 \cdot 82$ & 8.93 & $14 \cdot 35$ & $28 \cdot 84$ & $18 \cdot 51$ & $40 \cdot 25$ & $24 \cdot 45$ \\
\hline Girls (51.3\%) & $15 \cdot 92$ & $9 \cdot 30$ & $22 \cdot 50$ & $17 \cdot 86$ & 0.92 & $1 \cdot 89$ & 3.58 & $9 \cdot 41$ & $16 \cdot 85$ & $9 \cdot 88$ & $26 \cdot 08$ & $20 \cdot 69$ \\
\hline Low SES (28.2\%) & $21 \cdot 88$ & $15 \cdot 67$ & $25 \cdot 54$ & $17 \cdot 37$ & $1 \cdot 27$ & $2 \cdot 43$ & $7 \cdot 02$ & $15 \cdot 00$ & $23 \cdot 15$ & $16 \cdot 21$ & $32 \cdot 55$ & $22 \cdot 61$ \\
\hline \multirow[t]{3}{*}{ High SES $(71 \cdot 8 \%)$} & $20 \cdot 27$ & $13 \cdot 69$ & $26 \cdot 27$ & $19 \cdot 37$ & $1 \cdot 22$ & $2 \cdot 35$ & $6 \cdot 07$ & $11 \cdot 70$ & $21 \cdot 50$ & $14 \cdot 73$ & $32 \cdot 34$ & $23 \cdot 53$ \\
\hline & \multicolumn{4}{|c|}{ MPA (min/weekday) } & \multicolumn{4}{|c|}{ VPA (min/weekday) } & \multicolumn{4}{|c|}{ MVPA (min/weekday) } \\
\hline & \multicolumn{2}{|c|}{ CSA } & \multicolumn{2}{|c|}{$\mathrm{CSA}+\mathrm{NWA}$} & \multicolumn{2}{|c|}{ CSA } & \multicolumn{2}{|c|}{$\mathrm{CSA}+\mathrm{NWA}$} & \multicolumn{2}{|c|}{ CSA } & \multicolumn{2}{|c|}{$\mathrm{CSA}+\mathrm{NWA}$} \\
\hline Weekday & Mean & SD & Mean & SD & Mean & SD & Mean & SD & Mean & SD & Mean & SD \\
\hline Total sample (100\%) & $25 \cdot 59$ & $16 \cdot 73$ & $27 \cdot 63$ & $19 \cdot 14$ & $1 \cdot 30$ & $2 \cdot 56$ & $5 \cdot 64$ & $11 \cdot 82$ & $24 \cdot 90$ & $17 \cdot 72$ & $33 \cdot 27$ & $22 \cdot 85$ \\
\hline Boys (48.7\%) & $29 \cdot 68$ & $14 \cdot 45$ & $32 \cdot 49$ & $20 \cdot 08$ & $1 \cdot 67$ & $2 \cdot 91$ & $7 \cdot 71$ & $13 \cdot 35$ & $31 \cdot 35$ & $20 \cdot 57$ & $40 \cdot 20$ & $23 \cdot 50$ \\
\hline Girls (51·3\%) & $17 \cdot 81$ & $10 \cdot 89$ & $23 \cdot 00$ & $16 \cdot 98$ & 0.95 & $2 \cdot 13$ & 3.67 & $9 \cdot 78$ & $18 \cdot 77$ & $11 \cdot 56$ & $26 \cdot 68$ & $20 \cdot 15$ \\
\hline Low SES (28.2\%) & $24 \cdot 32$ & $18 \cdot 12$ & $27 \cdot 68$ & $19 \cdot 28$ & $1 \cdot 41$ & $2 \cdot 79$ & $6 \cdot 11$ & $13 \cdot 72$ & $25 \cdot 73$ & $18 \cdot 72$ & $33 \cdot 79$ & $23 \cdot 32$ \\
\hline \multirow[t]{3}{*}{ High SES $(71.8 \%)$} & $22 \cdot 28$ & $15 \cdot 19$ & $26 \cdot 53$ & $17 \cdot 88$ & $1 \cdot 20$ & $2 \cdot 43$ & $5 \cdot 76$ & $11 \cdot 59$ & $23 \cdot 48$ & $16 \cdot 30$ & $32 \cdot 29$ & $22 \cdot 16$ \\
\hline & \multicolumn{4}{|c|}{ MPA (min/weekend day) } & \multicolumn{4}{|c|}{ VPA (min/weekend day) } & \multicolumn{4}{|c|}{ MVPA (min/weekend day) } \\
\hline & \multicolumn{2}{|c|}{ CSA } & \multicolumn{2}{|c|}{$\mathrm{CSA}+\mathrm{NWA}$} & \multicolumn{2}{|c|}{ CSA } & \multicolumn{2}{|c|}{$\mathrm{CSA}+\mathrm{NWA}$} & \multicolumn{2}{|c|}{ CSA } & \multicolumn{2}{|c|}{$\mathrm{CSA}+\mathrm{NWA}$} \\
\hline Weekend day & Mean & SD & Mean & SD & Mean & SD & Mean & SD & Mean & SD & Mean & SD \\
\hline Total sample (100\%) & $16 \cdot 13$ & $18 \cdot 42$ & $24 \cdot 71$ & $35 \cdot 33$ & $1 \cdot 32$ & $3 \cdot 87$ & $7 \cdot 56$ & $20 \cdot 69$ & $17 \cdot 44$ & $19 \cdot 97$ & $32 \cdot 27$ & $40 \cdot 64$ \\
\hline Boys (48·7\%) & $21 \cdot 50$ & $21 \cdot 70$ & $28 \cdot 38$ & $35 \cdot 40$ & $1 \cdot 85$ & $4 \cdot 75$ & 11.98 & $25 \cdot 92$ & $23 \cdot 35$ & $23 \cdot 71$ & $40 \cdot 36$ & $42 \cdot 96$ \\
\hline Girls (51.3\%) & $11 \cdot 02$ & $12 \cdot 71$ & $21 \cdot 22$ & $34 \cdot 39$ & $0 \cdot 81$ & $2 \cdot 70$ & $3 \cdot 37$ & $12 \cdot 71$ & $11 \cdot 83$ & $13 \cdot 44$ & $24 \cdot 58$ & $36 \cdot 77$ \\
\hline Low SES (28.2\%) & $15 \cdot 77$ & $18 \cdot 24$ & $20 \cdot 18$ & $26 \cdot 02$ & 0.94 & $2 \cdot 90$ & $9 \cdot 28$ & 24.93 & $16 \cdot 71$ & $19 \cdot 09$ & $29 \cdot 46$ & $36 \cdot 31$ \\
\hline High SES (71.8\%) & $15 \cdot 71$ & $17 \cdot 59$ & $25 \cdot 62$ & $37 \cdot 75$ & $1 \cdot 34$ & $3 \cdot 84$ & $6 \cdot 85$ & $18 \cdot 98$ & $17 \cdot 05$ & $19 \cdot 13$ & $32 \cdot 46$ & $41 \cdot 47$ \\
\hline
\end{tabular}

total week and weekday mean number of minutes, the increase in MPA after including the non-wear activities was larger in girls, while for VPA a larger increase was found in boys.

For weekend day summary variables, a significant NWA-by-gender interaction effect was found for VPA $\left(F_{\mathrm{NWA} \times \mathrm{G}}=17 \cdot 0, P \leq 0 \cdot 001\right)$. Again, the increase was larger in boys. No significant NWA-by-gender interaction effect was found for weekend day MPA. No significant NWA-by-gender interaction effects were found for total week, weekday and weekend day MVPA. Furthermore, no significant NWA-by-SES interaction effects for total week, weekday and weekend day summary variables were found.

Bland-Altman plots visualizing the agreement between PA data with and without inclusion of the non-wear activities are displayed in Fig. 2. A lack of agreement exists between the mean minutes of MPA, VPA and MVPA with and without inclusion of non-wear activities for weekdays, weekend days and total week. The mean error of bias varied between $4 \cdot 0 \mathrm{~min} / \mathrm{d}$ and $13 \cdot 1 \mathrm{~min} / \mathrm{d}$. The lowest level of agreement was found for MVPA on weekend days. The results of the Pearson's correlation analyses showed a significant relationship between the difference in MPA, VPA and MVPA for weekdays, weekend days and total week with and without the inclusion of non-wear activities and the average of both methods.
The error of bias increased as the time spent in a certain level of PA increased.

\section{Impact of non-wear activities on the classification of adolescents according to current physical activity recommendations}

Using the thresholds of Puyau et al. ${ }^{(45)}, 3 \cdot 2 \%$ met the PA recommendations without inclusion of non-wear activities compared with $13 \cdot 1 \%$ with inclusion of non-wear activities. Using the age-specific equation of Freedson ${ }^{(48)}, 57 \cdot 7 \%$ met the PA recommendations without inclusion of the non-wear activities compared with $64.7 \%$ with inclusion of the nonwear activities.

Furthermore, kappa statistics revealed that the proportion of agreement for meeting the PA recommendation with and without inclusion of non-wear activities was $38.5 \%$ and $87 \cdot 6 \%$ for the thresholds of Puyau et al. ${ }^{(45)}$ and Freedson ${ }^{(48)}$, respectively.

\section{Discussion}

The results of the present study revealed that including non-wear activities when using accelerometers in 13-15year-old adolescents has an impact on PA summary 

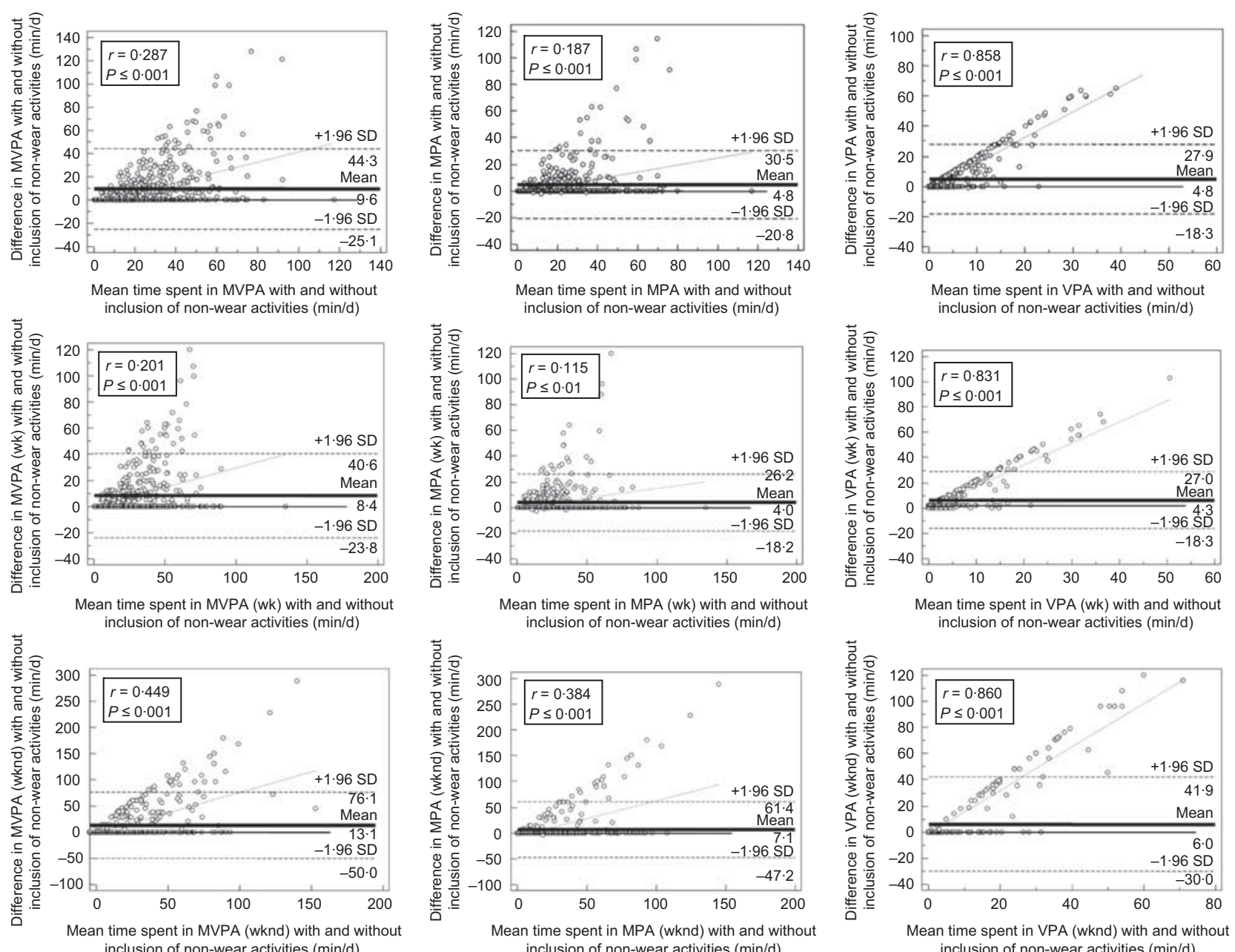

Fig. 2 Bland-Altman plots visualizing mean bias and levels of agreement for moderate-to-vigorous physical activity (MVPA; left column), moderate physical activity (MPA; middle column) and vigorous physical activity (VPA; right column) for the total week (top row), weekdays (wk; middle row) and weekend days (wknd; bottom row) with and without the inclusion of the activities recorded in the non-wear time activity diary: young adolescents ( $n 513 ; 48.6 \%$ boys) aged $13-15$ years, Ghent, Belgium, October $2008-M a y 2009$. - represents the mean difference; ----- represent the limit of agreement (mean bias $\pm 1.96 \mathrm{sD})$. Pearson's correlation coefficient $(r)$ and corresponding level of significance $(P)$ for the difference in MVPA, MPA and VPA for the total week, weekdays (wk) and weekend days (wknd) with and without the inclusion of the activities recorded in the non-wear time activity diary and the average

variables and the classification of adolescents according to PA recommendations.

As an increasing proportion of adolescents' leisure time consists of organized sports ${ }^{(54)}$ and those activities often prohibit activity monitors due to practical or safety regulations, it is not surprising that almost half of the adolescents registered at least one activity of moderate or vigorous intensity in the diary. Consequently, including non-wear activities led to significantly higher levels of MPA, VPA and MVPA. Furthermore, after inclusion of the non-wear activities, more adolescents met the PA recommendations irrespective of accelerometer thresholds used. This is especially important since a lack of consensus on the most suitable thresholds for analysing accelerometer data in adolescents exists.

These results confirm the hypothesis that combining accelerometers with diaries to register non-wear activities could lead to a more complete insight into the PA patterns of adolescents. It can improve the ability to accurately measure PA by reducing the known source of bias inherent to missing data of non-wear time. However, including non-wear activities does not result in significantly more individuals included in the study achieving the minimum recording requirements of registered time and number of valid days.

A more detailed insight into the data of the diaries revealed that there was no difference between the first and second monitoring day in the percentage of adolescents registering at least one activity of moderate or vigorous intensity in the diary and in the mean reported duration of non-wear activities. So there was no instrument reactivity.

More adolescents registered an activity performed on a weekday than on a weekend day and the mean registered 
minutes of MVPA were higher for weekend days than for weekdays. This result can be underpinned by the fact that the mean minutes of PA in which adolescent boys and girls participate are higher for activities performed on weekend days compared with activities performed on weekdays, while a greater proportion of adolescents report no engagement in PA on weekend days compared with weekdays ${ }^{(55,56)}$

The results of the present study imply that, in 13-15-yearolds, the additional information derived from non-wear time activity diaries is important to estimate PA levels in all adolescents regardless of SES. Furthermore, the additional information is as important in boys as in girls. The impact, however, is not totally comparable. The increase in VPA is most obvious in boys while the increase in MPA is most obvious in girls. This finding can be substantiated by a previous study ${ }^{(34)}$ reporting that the intensity of everyday activities is systematically lower in girls than in boys. No gender differences were apparent for MVPA. Evidently, the increase in MPA counterbalanced the increase in VPA.

Bland-Altman plots indicated that the differences in summary variables with and without inclusion of non-wear activities increased as the time spent in PA increased. This may be due to the fact that individuals with higher PA levels engage in more activities for which accelerometers must be removed. Further examination of this issue is required.

The present study gives more insight into how to deal with potential issues of bias which are related with nonwear time when using accelerometers in adolescents. The study's results are in line with those of Ottevaere et al. ${ }^{(27)}$ in 12-18-year-olds. In the present study, the age range of the sample was narrowed to $13-15$ years assuming that the prevalence of sports participation is noticeable in the non-wear time when using accelerometers. In young adolescence ( $\leq 15$ years), sports participation remains rather unchanged while from the age of 15 years the decline in sports participation is characterized by a particular steepness. Consequently, the impact of non-wear activities is almost twice as large in the present study compared with the study of Ottevaere et $a l^{(27)}$.

In addition, the present study consisted of a larger sample not acquainted with the specific research questions of the study and examined possible differences in impact of nonwear activities according to gender, SES, level of PA and day of the week (weekday, weekend day).

Still, the findings of the present study should be interpreted in light of the following limitations. First, non-wear time activity diaries are not able to resolve all problems concerning underestimation of PA with accelerometers. Using accelerometers, specific activities and movements associated with non-ambulatory activity, such as cycling, are recorded as little or no activity ${ }^{(48,57)}$. Furthermore, the accuracy of diaries totally depends on the compliance of the participants. The diary used in our study was easy to fill in and required less than $5 \mathrm{~min} / \mathrm{d}$. However, filling in non-wear time activities can easily be forgotten. Although $60 \%$ of the periods of non-wear time measured by the accelerometers was registered in the diaries, it could be recommended to use reminders (e.g. messages through email or mobile phone) to increase compliance of the diaries and length of wear time of the accelerometers, to improve the assessment of overall PA and the ability to express activities as a proportion of waking hours. Furthermore, an electronic version of the diary can also be a possibility to meet the living environment of adolescents.

Although the present study confirms the impact of nonwear activities when using accelerometry, it cannot be ignored that inclusion of subjective data when using an objective assessment method can have some consequences. Therefore, studies examining the advantages and disadvantages of combining data from subjective diaries and objective accelerometers (e.g. participant and researcher burden to complete and analyse diaries, percentage of overestimation of registered non-wear time activities, sensitivity and specificity of the correction factors used) are needed to help determine if the advantages outweigh the disadvantages.

\section{Conclusions}

Almost half of the 13-15-year-olds registered MVPA in the non-wear time activity diaries. The registered activities were particularly aquatic activities and ball games. More adolescents registered MVPA performed on a weekday than on a weekend day and the mean minutes of MVPA registered in the diaries were higher for weekend days than for weekdays. The inclusion of non-wear activities had a notable impact on PA summary variables regardless of adolescents' SES or gender and more adolescents achieved the PA recommendations after inclusion of the non-wear activities irrespective of accelerometer thresholds used. Based on these findings, it is clear that the combination of accelerometers with non-wear activity diaries can lead to different PA outcomes at the individual level and therefore can improve the ability to accurately measure PA.

However, further research is necessary to assess the impact of non-wear activities in other age groups, to investigate the compliance to the protocol of non-wear time activity diaries and to examine the advantages and disadvantages of combining data from subjective diaries and objective accelerometers.

\section{Acknowledgements}

This work was supported by a Ghent University Special Research Fund (BOF; grant number BOF 08/24J/134). The authors declare that they have no competing interests. F.D.M. coordinated the data collection, assisted in the recruitment of the participants, conducted the statistical analyses and drafted the manuscript. G.C., I.D.B., B.D. and 
C.O. participated in the interpretation of the data, revised the draft versions of the manuscript and provided critical comments during the process. All authors read and approved the final version of the manuscript. The authors wish to acknowledge the contribution of Tom Blanchaert, Ben De Baets, Philippe De Bruycker, Tomas De Lange, Justien Desodt, Sharon Lagast, Dorine Meersschaut, Lieselot Rys, Liza Schelfaut, Ilse Ulenaers and Marijke Van Slycken in the data collection. They also wish to thank the adolescents for their participation in the study.

\section{References}

1. Andersen LB, Sardinha LB, Froberg K et al. (2008) Fitness, fatness and clustering of cardiovascular risk factors in children from Denmark, Estonia and Portugal: the European Youth Heart Study. Int J Pediatr Obes 3, Suppl 1, 58-66.

2. Ekelund U, Anderssen SA, Froberg K et al. (2007) Independent associations of physical activity and cardiorespiratory fitness with metabolic risk factors in children: the European youth heart study. Diabetologia 50, 1832-1840.

3. Janssen I \& Leblanc AG (2010) Systematic review of the health benefits of physical activity and fitness in schoolaged children and youth. Int J Behav Nutr Phys Act 7, 40.

4. Hallal PC, Victora CG, Azevedo MR et al. (2006) Adolescent physical activity and health: a systematic review. Sports Med 36, 1019-1030

5. Warburton DE, Nicol CW \& Bredin SS (2006) Health benefits of physical activity: the evidence. CMAJ 174, 801-809.

6. Strong WB, Malina RM, Blimkie CJ et al. (2005) Evidence based physical activity for school-age youth. J Pediatr 146, 732-737.

7. Wareham NJ \& Rennie KL (1998) The assessment of physical activity in individuals and populations: why try to be more precise about how physical activity is assessed? Int J Obes Relat Metab Disord 22, Suppl 2, S30-S38.

8. Reilly JJ, Penpraze V, Hislop J et al. (2008) Objective measurement of physical activity and sedentary behaviour: review with new data. Arch Dis Child 93, 614-619.

9. Rowlands AV (2007) Accelerometer assessment of physical activity in children: an update. Pediatr Exerc Sci 19, 252-266.

10. de Vries SI, Van Hirtum HW, Bakker I et al. (2009) Validity and reproducibility of motion sensors in youth: a systematic update. Med Sci Sports Exerc 41, 818-827.

11. Cooper A, Page A, Wheeler B et al. (2010) Patterns of GPS measured time outdoors after school and objective physical activity in English children: the PEACH project. Int J Behav Nutr Phys Act 7, 31.

12. Haerens L, Deforche B, Maes L et al. (2006) Evaluation of a 2-year physical activity and healthy eating intervention in middle school children. Health Educ Res 21, 911-921.

13. Kien CL \& Chiodo AR (2003) Physical activity in middle school-aged children participating in a school-based recreation program. Arch Pediatr Adolesc Med 157, 811-815.

14. Kolle E, Steene-Johannessen J, Andersen L et al. (2009) Seasonal variation in objectively assessed physical activity among children and adolescents in Norway: a crosssectional study. Int J Behav Nutr Phys Act 6, 36.

15. Riddoch CJ, Mattocks C, Deere K et al. (2007) Objective measurement of levels and patterns of physical activity. Arch Dis Child 92, 963-969.

16. Masse LC, Fuemmeler BF, Anderson CB et al. (2005) Accelerometer data reduction: a comparison of four reduction algorithms on select outcome variables. Med Sci Sports Exerc 37, 11 Suppl., S544-S554.
17. Crocker P, Holowachuk D \& Kowalski NP (2001) Feasibility of using the Tritrac motion sensor over a 7-day trial with older children. Pediatr Exerc Sci 13, 70-81.

18. Corder K, Ekelund U, Steele RM et al. (2008) Assessment of physical activity in youth. J Appl Physiol 105, 977-987.

19. Colley R, Gorber SC \& Tremblay MS (2010) Quality control and data reduction procedures for accelerometry-derived measures of physical activity. Health Rep 21, 63-69.

20. Hagstromer M, Bergman P, De Bourdeaudhuij I et al. (2008) Concurrent validity of a modified version of the International Physical Activity Questionnaire (IPAQ-A) in European adolescents: The HELENA Study. Int J Obes (Lond) 32, Suppl 5, S42-S48.

21. van Sluijs EM, Page A, Ommundsen Y et al. (2010) Behavioural and social correlates of sedentary time in young people. Br J Sports Med 44, 747-755.

22. Jago R, Baranowski T, Baranowski JC et al. (2006) Fit for Life Boy Scout badge: outcome evaluation of a troop and Internet intervention. Prev Med 42, 181-187.

23. Catellier DJ, Hannan PJ, Murray DM et al. (2005) Imputation of missing data when measuring physical activity by accelerometry. Med Sci Sports Exerc 37, 11 Suppl., S555-S562.

24. Cardon GM, de Clercq DL, Geldhof EJ et al. (2007) Back education in elementary schoolchildren: the effects of adding a physical activity promotion program to a back care program. Eur Spine J 16, 125-133.

25. Schneider M, Dunn A \& Cooper D (2009) Affect, exercise, and physical activity among healthy adolescents. J Sport Exerc Psychol 31, 706-723.

26. Gaya AR, Alves A, Aires L et al. (2009) Association between time spent in sedentary, moderate to vigorous physical activity, body mass index, cardiorespiratory fitness and blood pressure. Ann Hum Biol 36, 379-387.

27. Ottevaere C, Huybrechts I, De Meester F et al. (2011) The use of accelerometry in adolescents and its implementation with non-wear time activity diaries in free-living conditions. J Sports Sci 29, 103-113.

28. Michaud PA, Narring F, Cauderay M et al. (1999) Sports activity, physical activity and fitness of 9- to 19-year-old teenagers in the canton of Vaud (Switzerland). Schweiz Med Wochenschr 129, 691-699.

29. Stubbe JH, Boomsma DI \& De Geus EJ (2005) Sports participation during adolescence: a shift from environmental to genetic factors. Med Sci Sports Exerc 37, 563-570.

30. Slater A \& Tiggemann M (2011) Gender differences in adolescent sport participation, teasing, self-objectification and body image concerns. J Adolesc 34, 455-463.

31. Seabra AF, Mendonca DM, Thomis MA et al. (2008) Associations between sport participation, demographic and socio-cultural factors in Portuguese children and adolescents. Eur J Public Health 18, 25-30.

32. de Vries SI, Bakker I, Hopman-Rock M et al. (2006) Clinimetric review of motion sensors in children and adolescents. J Clin Epidemiol 59, 670-680.

33. Actigraph R\&D and Software Departments (2011) Actilife User's Manual v5.0.0. http://dl.theactigraph.com/ActiLife5-PUB 10DOC10-H.pdf

34. Bringolf-Isler B, Grize L, Mader U et al. (2009) Assessment of intensity, prevalence and duration of everyday activities in Swiss school children: a cross-sectional analysis of accelerometer and diary data. Int J Behav Nutr Phys Act 6, 50.

35. Sanchez A, Norman GJ, Sallis JF et al. (2007) Patterns and correlates of physical activity and nutrition behaviors in adolescents. Am J Prev Med 32, 124-130.

36. Timperio A, Giles-Corti B, Crawford D et al. (2008) Features of public open spaces and physical activity among children: findings from the CLAN study. Prev Med 47, 514-518.

37. Ridley K, Ainsworth BE \& Olds TS (2008) Development of a compendium of energy expenditures for youth. Int J Behav Nutr Phys Act 5, 45. 
38. Harrell JS, McMurray RG, Bangdiwala SI et al. (2003) Determining MET values in children and adolescents. Med Sci Sports Exerc 35, issue 5, S342.

39. Ainsworth BE, Haskell WL, Whitt MC et al. (2000) Compendium of physical activities: an update of activity codes and MET intensities. Med Sci Sports Excerc 32, 9 Suppl., S498-S504.

40. Fairclough S \& Stratton G (2005) Physical activity levels in middle and high school physical education: a review. Pediatr Exerc Sci 17, 217-236.

41. Rowlands AV, Pilgrim EL \& Eston RG (2008) Patterns of habitual activity across weekdays and weekend days in 9-11-year old children. Prev Med 46, 317-324

42. Corder K, Van Sluijs EM, Goodyer I et al. (2011) Physical activity awareness of British adolescents. Arch Pediatr Adolesc Med 165, 603-609.

43. Treuth MS, Schmitz K, Catellier DJ et al. (2004) Defining accelerometer thresholds for activity intensities in adolescent girls. Med Sci Sports Exerc 36, 1259-1266.

44. Freedson PS, Melanson E \& Sirard J (1998) Calibration of the Computer Science and Applications, Inc. accelerometer. Med Sci Sports Exerc 30, 777-781.

45. Puyau M, Adolph A \& Vohra F (2002) Validation and calibration of physical activity monitors in children. Obes Res 10, 150-157.

46. Ward DS, Evenson KR, Vaughn A et al. (2005) Accelerometer use in physical activity: best practices and research recommendations. Med Sci Sports Exerc 37, 11 Suppl., S582-S588.

47. Trost SG, Loprinzi PD, Moore R et al. (2011) Comparison of accelerometer cut-points for predicting activity intensity in youth. Med Sci Sports Exerc 43, 1360-1368.
48. Freedson P (2005) Calibration of accelerometer output for children. Med Sci Sports Exerc 37, 11 Suppl., S523-S530.

49. Brand S, Hatzinger M, Beck J et al. (2009) Perceived parenting styles, personality traits and sleep patterns in adolescents. J Adolesc 32, 1189-1207.

50. Trost SG, Pate RR, Freedson PS et al. (2000) Using objective physical activity measures with youth: how many days of monitoring are needed? Med Sci Sports Exerc 32, 426-431.

51. Trost SG, McIver KL \& Pate RR (2005) Conducting accelerometer-based activity assessments in field-based research. Med Sci Sports Exerc 37, 11 Suppl., S531-S543.

52. Shavers VL (2007) Measurement of socioeconomic status in health disparities research. J Natl Med Assoc 99, 1013-1023.

53. Bland JM \& Altman DG (1986) Statistical methods for assessing agreement between two methods of clinical measurement. Lancet 1, 307-310.

54. Laakso L, Telama R, Nupponen H et al. (2008) Trends in leisure time physical activity among young people in Finland, 1977-2007. Eur Phys Educ Rev 14, 139-155.

55. Gorely T, Marshall SJ, Biddle SJ et al. (2007) The prevalence of leisure time sedentary behaviour and physical activity in adolescent girls: an ecological momentary assessment approach. Int J Pediatr Obes 2, 227-234.

56. Gorely T, Biddle SJ, Marshall SJ et al. (2009) The prevalence of leisure time sedentary behaviour and physical activity in adolescent boys: an ecological momentary assessment approach. Int J Pediatr Obes 4, 289-298.

57. Corder K, Brage S, Mattocks C et al. (2007) Comparison of two methods to assess PAEE during six activities in children. Med Sci Sports Exerc 39, 2180-2188. 